\title{
Phenotype, Inheritance, and Regulation of Expression of a New Virescent Mutant in Watermelon: Juvenile Albino
}

\author{
X.P. Zhang, B.B. Rhodes, and W.V. Baird \\ Department of Horticulture, Clemson University, Clemson, SC 29634 \\ H.T. Skorupska \\ Department of Agronomy and Soils and Department of Biological Sciences, Clemson University, \\ Clemson, SC 29634
}

W.C. Bridges

Department of Experimental Statistics, Clemson University, Clemson, SC 29634

Additional index words. breeding, Citrullus lanatus, chlorophyll-deficiency, hybrid, photoperiod sensitivity, seed production

\begin{abstract}
Juvenile albino, gene symbol $j a$, is a spontaneous virescent mutant, first observed in 'Dixielee' and an $\mathrm{F}_{2}$ population of 'G17AB' (msms) X 'Dixielee' in 1992. Hypocotyls, new young leaves, shoot tips, tendrils and flowers on the main shoot of the ja mutant are all albino during early spring. The interior portions of albino leaves gradually become green, while the margins remain albino. Fruit rind color of the mutant is variegated. Growth of the ja mutant is severely impaired in the early spring. However, the mutant grows at a rate comparable to wild-type in the summer, and produces fruit of almost normal size. Genetic analysis of $\mathrm{F}_{1}, \mathrm{~F}_{2}$, and $\mathrm{BC}_{1}$ populations derived from the ja mutant showed that the gene for the ja mutant is inherited as a single, recessive, nuclear gene. Segregation ratios in the $\mathrm{F}_{2}$ and $\mathrm{BC}_{1}$ progenies derived from the cross between the previously reported delayed green virescent mutant and the ja mutant indicate independent inheritance of the genes $d g$ and $j a$. Temperature and red/far-red light had no differential effect on mutant and the wild-type plants. An increase of daylength from 8 to 15 hours increased fresh weight and chlorophyll content more in the ja mutant than in the wild-type. The mutant had a higher chlorophyll a $: \mathrm{b}$ ratio than the wild-type under long days. Chlorophyll synthesis or accumulation in the mutant is severely impaired under short days. This is the only virescent mutant in the family Cucurbitaceae whose expression is regulated by daylength.
\end{abstract}

A virescent mutant is a pigment-deficient mutant in which deficiencies or alterations in the photosynthetic apparatus may be modified by environmental factors (Hopkins et al., 1980). Virescent mutants are useful for studying photosynthesis (Somerville, 1986), interactions between nuclear and plastid genomes (Taylor, 1989; Wetzel et al., 1994), gene flow in experimental populations (Handel, 1982), and for developing linkage maps (McCreight and Bohn, 1979; Whelan et al., 1975; Zink, 1977). Also, virescent mutants can be used as seedling markers for hybrid seed production and backcross breeding without hand-pollination (Nugent and Hoffman, 1981; Nugent, 1994; Zhang et al., 1996).

Four spontaneous chlorophyll-deficient mutants have been described in watermelon (Provvidenti, 1994; Rhodes, 1986; Rhodes and Zhang, 1995; Robinson et al., 1976). Delayed-green ( $d g$ ) (Rhodes, 1986), is characterized by pale-green cotyledons and new leaves that turn green as development progresses. The $d g$ mutation is inherited as a single recessive gene, $d g$ (Zhang et al., 1996). Spotted mutation, inherited as a single dominant gene, $S p$, results in yellow spots on cotyledons, leaves and fruit (Rhodes, 1986). Yellow $(\mathrm{Yl})$, an incompletely dominant gene, produces yellow leaves with reduced chlorophyll content (Warid and AbdEl-Hafez, 1976). Seedling leaf variegation (slv), a single recessive gene, causes whitish-green cotyledons and mosaic-like variegated leaves at the seedling stage under low temperature $\left(<20^{\circ} \mathrm{C}\right)$. This

Received for publication 23 Oct. 1995. Accepted for publication 20 Feb. 1996. This article is technical contribution no. 4125 of the South Carolina Agricultural Experiment Station, Clemson Univ., Clemson, S.C. This work was supported in part by USDA-OICD. The cost of publishing this paper was defrayed in part by the payment of page charges. Under postal regulations, this paper therefore must be hereby marked advertisement solely to indicate this fact. type of chlorophyll deficiency at low temperature is common in cultivated watermelons (Provvidenti, 1994).

In 1992, we observed a new virescent mutant, juvenile albino (ja) in two populations, the self-pollinated 'Dixielee' and an $F_{2}$ population of 'G17AB' (msms) X 'Dixielee' (Zhang and Rhodes, 1994). The mutation $j a$ is believed to be spontaneous, originating in 'Dixielee'. This is substantiated by the fact that ja plants existed in an $F_{2}$ population of ' $R 309$ ' $x$ 'Dixielee', which was tested in 1995 , but the crosses were initiated at the same time as the 'G17AB' (msms) X 'Dixielee' cross. 'R309' is a selection belonging to Citrullus colocynthis (Rhodes et al., 1992).

Dramatic seasonal differences in albino phenotype expression were observed in the ja mutant. A ja plant of 'Dixielee' produced three fruit, each about $10 \mathrm{~kg}$, during Summer 1993. However, this plant was nearly albino when grown in the greenhouse in early February and was moved into a growth chamber to rescue it. Understanding the regulation of $j a$ expression is, therefore, as important as understanding the inheritance of the mutation. We report here the phenotypic characteristics of the ja mutant; inheritance of the ja mutation; the genetic relationship between $j a$ and $d g$; and the regulation of $j a$ expression. Potential applications of the ja mutant to watermelon genetics and breeding are also discussed.

\section{Materials and Methods}

Phenotype characterization of the ja mutant was conducted from Spring 1992 to Fall 1994 in the field at Edisto Research and Education Center (EREC) of Clemson Univ., Blackville, S.C., and in the greenhouse on the main campus of Clemson Univ. The ja mutant and the wild-type of cultivar 'Dixielee' were used primarily for phenotype characterization. To study the consistency of ja 
phenotype in different genetic backgrounds, ja mutants derived from the $\mathrm{F}_{2}$ populations of $20 \mathrm{~J} 57$ ( $\left.\mathrm{JaJa}\right) \times$ 'Dixielee' (jaja) and 'Sweet Princess' $(\mathrm{JaJa}) \times$ 'Dixielee' (jaja), and the population with pedigree [G17AB $\times($ G17AB $\times$ 'Dixielee' $)] \times(G 17 A B \times$ 'Dixielee') and genotypes msmsJaja $\times$ MsmsJaja, were examined in the field along with the wild-type in Spring-Summer 1993 at EREC.

Genetic studies were conducted to understand the inheritance of the $j a$ mutation and the genetic relationship between $j a$ and the previously reported virescent mutation $d g$, which has some phenotypic similarities to $j a$. Eight populations were examined for inheritance of the ja trait (Table 1). A population of self-pollinated heterozygous (Jaja) 'Dixielee' was tested in the greenhouse during Fall 1993. G17AB is a male-sterile line developed in China (Zhang and Wang, 1990; Zhang et al., 1994).

The genetic relationship between $j a$ and $d g$ was investigated using five populations grown in the greenhouse during late fall of 1993 (Table 2). Comparison of the observed segregation ratio and the expected ratio was accomplished using a chi-square analysis.

Three experiments were conducted to assess the effect of temperature, daylength, and end of day (EOD) light on juvenile albino phenotypic expression. Seeds of 'Dixielee' (normal) and ja mutant were planted in Todd planter flats (no. 14-2574; A.H. Hummert Seed Co., St. Louis) containing premoistened commercial soilless potting mix (Mix No. 2. Fafard, Inc., Anderson, S.C.) and placed into a growth chamber (model E15; Controlled Environments Ltd., Winnipeg, Manitoba, Canada) with photosynthetic photon flux (PPF) of 40 to $300 \mu \mathrm{mol} \cdot \mathrm{m}^{-2} \cdot \mathrm{s}^{-1}$ for a $15-\mathrm{h}$ period and temperatures of 23 (night) to $32{ }^{\circ} \mathrm{C}$ (day). The light ramp was programmed to increase the PPF from 40 to 300 and to decrease from 300 to $40 \mu \mathrm{mol} \cdot \mathrm{m}^{-2} \cdot \mathrm{s}^{-1}$ in a period of $2.5 \mathrm{~h}$, respectively. A completely randomized design with four replications was used for each of these three experiments. Uniform seedlings of each genotype were selected from those raised in the growth chamber, and assigned to the experiment units, each consisting of four seedlings. Two days before the initiation of treatments, seedlings were transplanted into 5.6×5.6 ×5.6-cm Kord Inserts (no. 6761-8, Park Seed Wholesale, Greenwood, S.C.) containing a sterilized mix of vegetable garden topsoil and fine sand (3:1).

The first experiment was designed to determine if temperature affects ja expression. Ten-day-old seedlings were used for this experiment. All seedlings were kept in the growth chamber with a daytime $(15 \mathrm{~h})$ temperature of 25 to $32^{\circ} \mathrm{C}$ and PPF of 40 to 300 umol $\cdot \mathrm{m}^{-2} \cdot \mathrm{s}^{-1}$. Nighttime $(9 \mathrm{~h})$ temperature treatments were low $(5$ $\left.\pm 2{ }^{\circ} \mathrm{C}\right)$ or high $\left(23 \pm 2{ }^{\circ} \mathrm{C}\right)$. The high temperature treatment was conducted in the growth chamber, and the cold treatment was conducted in a dual-program illuminated incubator (Precision Scientific Group, GCA Cooperation, Chicago). After 10 days, total fresh weight and seedling height were determined.

The second experiment was conducted to determine if daylength affects ja expression. Two-week-old growth chamber-grown seedlings were used for this experiment. Two alternative photoperiods, but with balanced total energy input, were used. The long-day treatment consisted of $8 \mathrm{~h}$ high PPF (200 to $\left.300 \mu \mathrm{mol} \cdot \mathrm{m}^{-2} \cdot \mathrm{s}^{-1}\right)$ and $7 \mathrm{~h}$ below the accepted compensation point, with a PPF of 20 to 40 $\mu \mathrm{mol} \cdot \mathrm{m}^{-2} \cdot \mathrm{s}^{-1}$. The short-day treatment consisted of $8 \mathrm{~h}$ of the high PPF only. After 10 days, shoot fresh weight and leaf chlorophyll content were determined. Chlorophyll content was assayed on a spectrophotometer (SPECTRONIC 1001; Bausch \& Lomb, Rochester, N.Y.). Chlorophyll was extracted in $80 \%$ acetone as described by Witham at al. (1971). Total chlorophyll, chlorophyll a, and chlorophyll b content of the extract were calculated according to the formulae of Witham et al. (1971). One gram of leaf tissue was collected from each seedling, and six seedlings were randomly sampled for each treatment and genotype.

The third experiment was conducted to determine if phytochrome is involved in the regulation of $j a$ expression. Seven-dayold seedlings of 'Dixielee' ja mutant and the wild-type were used in this experiment. The treatment methods and conditions were similar to those described by Decoteau and Friend (1991). Plants were provided $300 \mu \mathrm{mol} \cdot \mathrm{m}^{-2} \cdot \mathrm{s}^{-1}$ PPF during an 8 -h period of day in the laboratory equipped with a multi-vapor HID light (General Electric Corp.). The day/night temperature cycle averaged 27/21 ${ }^{\circ} \mathrm{C}$. At the end of this daily 8 -h photoperiod, the seedlings were briefly (15 min each light type) exposed to red (R), far-red (FR), R + FR (i.e., 15 min R followed by 15 min FR light treatment), FR $+\mathrm{R}$ (i.e., $15 \mathrm{~min}$ FR followed by $15 \mathrm{~min} \mathrm{R}$ light treatment), or directly placed in dark (control). $\mathrm{R}$ light exposure $\left(2.8 \mathrm{~W} \cdot \mathrm{m}^{-2}\right.$ in the 600 to $700 \mathrm{~nm}$ waveband) was obtained by filtering radiation from six cool-white, 40-W fluorescent lamps through a Roscolux no. 19 acetate filter (Rosco, Port Chester, N.Y.). FR light exposure (10 $\mathrm{W} \cdot \mathrm{m}^{-2}$ in the 700 to $780 \mathrm{~nm}$ waveband) was obtained by filtering radiation from two 150-W internal-reflector, incandescent lamps through a polyacrylic sheet of cast acrylic no. 2711, dark red (Rohm and Haas, Bristol, Pa.). After 10 days, fresh weight, hypocotyl length, and petiole length were determined.

Table 1. Summary of juvenile albino mutant inheritance study ${ }^{\mathrm{z}}$.

\begin{tabular}{|c|c|c|c|c|c|c|c|c|}
\hline \multirow[b]{2}{*}{ Pedigree } & \multirow[b]{2}{*}{ Genotype } & \multirow[b]{2}{*}{ Generation } & \multirow[b]{2}{*}{ Season $^{\mathrm{y}}$} & \multicolumn{2}{|c|}{ Phenotype } & \multirow[b]{2}{*}{$\begin{array}{l}\text { Expected } \\
\text { ratio }\end{array}$} & \multirow[b]{2}{*}{$\chi^{2}$} & \multirow[b]{2}{*}{$P$ value } \\
\hline & & & & Normal & $\begin{array}{l}\text { Juvenile } \\
\text { albino }\end{array}$ & & & \\
\hline Dixielee & jaja & $\mathrm{P}_{1}$ & $\mathrm{Sp}$ & 0 & 100 & & & \\
\hline $20 \mathrm{~J} 57$ & $J a J a$ & $\mathrm{P}_{2}$ & $\mathrm{Sp}$ & 25 & 0 & & & \\
\hline 20J57 x Dixielee & JaJa $\times$ jaja & $\mathrm{P}_{1} \times \mathrm{P}_{2}$ & $\mathrm{Sp}$ & 25 & 0 & & & \\
\hline$(20 J 57 \times$ Dixielee $) \times$ Dixielee & $($ JaJa $\times$ jaja $) \times$ jaja & $\mathrm{F}_{1} \times \mathrm{P}_{1}^{2}$ & $\mathrm{Sp}$ & 117 & 119 & $1: 1$ & 0.02 & 0.90 \\
\hline$(20 J 57 \times$ Dixielee $) \otimes$ & $(J a J a \times j a j a) \otimes$ & $\mathrm{F}_{2}$ & $\mathrm{Sp}$ & 457 & 147 & $3: 1$ & 0.04 & 0.71 \\
\hline Heterozygous Dixielee $\otimes$ & $($ Jaja $) \otimes$ & $\begin{array}{c}2 \\
---\end{array}$ & $\mathrm{F} ; \mathrm{Sp}$ & 96 & 34 & $3: 1$ & 0.09 & 0.76 \\
\hline $\begin{array}{l}(\text { Sweet Princess } \times \text { Dixielee }) \otimes \\
{[\text { G17AB } \times(G 17 \mathrm{AB} \times \text { Dixielee })]}\end{array}$ & $(J a J a \times j a j a) \otimes$ & $\mathrm{F}_{2}$ & SS & 209 & 64 & $3: 1$ & 0.35 & 0.55 \\
\hline x (G17AB $\times$ Dixielee $)$ & msmsJaja $\times$ MsmsJaja & --- & SS & 128 & 42 & $3: 1$ & 0.01 & 0.93 \\
\hline
\end{tabular}

'Phenotypes of progenies of 'Dixielee', 20J57, 20J57 x 'Dixielee', (20J57 x 'Dixielee') X 'Dixielee' and (20J57 x 'Dixielee') $F_{2}$ were tested in the greenhouse at seedling stage. Phenotypes of progenies of self-pollinated heterozygous 'Dixielee' ( Jaja), (Sweet Princess X 'Dixielee') $F_{2}$, and [G17AB X (G17AB x 'Dixielee')] x (G17AB x 'Dixielee') were determined from seedlings grown in the field.

${ }^{\mathrm{y}}$ Season: spring $=\mathrm{Sp}$; spring-summer $=\mathrm{SS}$; fall $=\mathrm{F}$. 


\begin{tabular}{|c|c|c|c|c|c|c|c|c|}
\hline \multirow[b]{2}{*}{ Pedigree } & \multirow[b]{2}{*}{ Genotype } & \multirow[b]{2}{*}{ Generation } & \multicolumn{3}{|c|}{ Phenotype } & \multirow[b]{2}{*}{$\begin{array}{l}\text { Expected } \\
\text { ratio }\end{array}$} & \multirow[b]{2}{*}{$\chi^{2}$} & \multirow[b]{2}{*}{$P$ value } \\
\hline & & & Normal & $\begin{array}{c}\text { Delayed } \\
\text { green }\end{array}$ & $\begin{array}{c}\text { Juvenile } \\
\text { albino }\end{array}$ & & & \\
\hline Dixielee & (jaja) & $\mathrm{P}_{1}$ & 0 & 0 & 36 & & & \\
\hline Pale90 & $(d g d g)$ & $\mathrm{P}_{2}$ & 0 & 38 & 0 & & & \\
\hline Pale90 x Dixielee & $($ dgdg $\times j a j a)$ & $\mathrm{F}_{1}$ & 35 & 0 & 0 & & & \\
\hline (Pale90 $\times$ Dixielee $) \times$ Dixielee & $($ dgdg $\times$ jaja $) \times j a j a$ & BC1 & 37 & 0 & 39 & $1: 1$ & 0.05 & 0.82 \\
\hline$($ Pale90 x Dixielee $) \otimes$ & $(d g d g \times$ jaja $) \otimes$ & $\mathrm{F}_{2}$ & 206 & 74 & 86 & $9: 3: 4$ & 0.75 & 0.59 \\
\hline
\end{tabular}

${ }_{\text {zPhenotypes of individuals involved in this study were determined at seedling stage. Phenotypes of individuals with jajadgdg and jajaDg_ were }}$ indistinguishable.

Temperature, daylength, and EOD light treatment were subjected to an ANOVA using the GLM procedure in SAS (SAS Institute, 1988).

\section{Results and Discussion}

Phenotype. The ja mutant is apparent as early as seedling emergence. Cotyledons are yellowish to light cream (Fig. 1) when seedlings first emerge from the soil and gradually turn greenishyellow. Variation in the expression of cotyledon color was observed among progeny seedlings in our homogeneous populations. The hypocotyl of the ja mutant is always pure white; in contrast, the wild-type hypocotyl is light green. Young leaves of the mutant, grown in spring/early summer in South Carolina, are yellowish to white. These albino leaves gradually become green as development progresses, but the margins of the leaves remain white, resulting in a chimeric appearance to mature leaves (Fig. 2). Shoot tips, tendrils, petioles, stems (Fig. 2) and flower petals (Fig. 3) of the mutant are white to light cream with a slight hint of green. Pollen grains from albino flowers are colorless, but viable. The stigmas are orange, apparently lacking chlorophyll. The ovary color varies from light green to pure white. Some portions of the fruit rind are unevenly yellow (Fig. 4), showing that rind color of mature fruit is also affected by the $j a$ gene.

Fig. 1. Seedlings of the juvenile albino watermelon mutant and the wild-type.

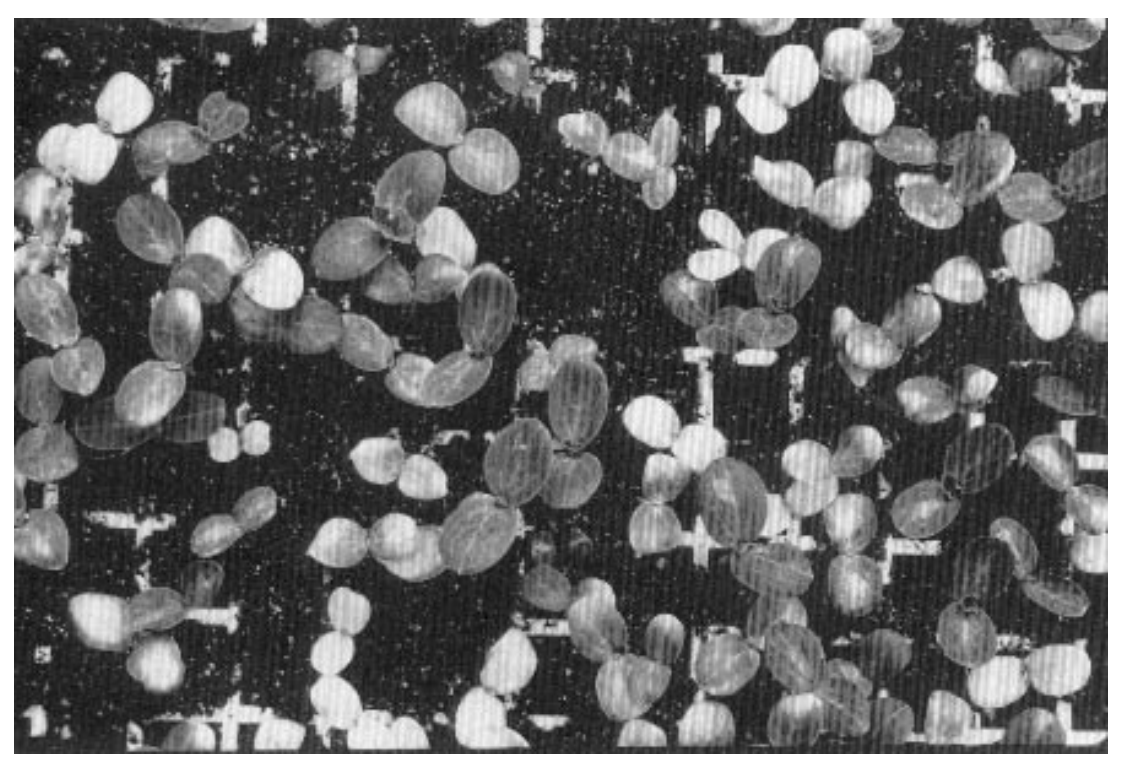

In addition to these chlorophyll differences, the flower petals of the ja mutant are considerably smaller than those of the wild-type. The petals of some flowers are not large enough to cover the stigma or anthers. Female fertility and fruit setting of the mutant is the same as that of the wild-type. No effect of the $j a$ gene on flesh color has been observed. Soluble solids content in the fruit of the ja mutant is comparable to that of wild-type (data not shown). The phenotypic characters of the ja mutant are very similar to the virescent $(v)$ mutant described by Hoffman and Nugent (1973) in melon. However the $v$ gene in melon also affects flesh color, producing salmon-like streaks in bright yellow flesh.

Growth of the ja mutant in early spring is severely impaired. Seedlings of the ja mutant grow very slow when they are planted in February and March in the greenhouse, and many of them die when it is cloudy and/or they receive too much water. Growth of the mutant plants improves as the season progresses, and in the summer they grow comparably to the wild-type. Branches produced from the main shoots in the summer are almost normal green (Fig. 2). Flowers produced by these branches are normal in color and size. Typical ja phenotypic characteristics were not observed from the homozygous 'Dixielee' ja seedlings planted in August in the greenhouse until later in September. Modification of $j a$ expression in different seasons has been observed in all genetic stocks where $j a$ was introduced. Seasonal variation of virescent expression was not noted in the $v$ melon mutant (Hoffman and Nugent, 1973).

Color modifications of cotyledon, hypocotyl, leaf, stem, flower, pollen and fruit rind in the ja mutant are most likely the result of chlorophyll deficiencies caused by the ja gene. Our current hypothesis is that the function of the ja gene is probably limited to impairing chlorophyll synthesis or accumulation.

Inheritance of juvenile albino. A cross between homozygous juvenile albino line and homozygous normal green produced a normal green $\mathrm{F}_{1}$ hybrid. Backcrossing the $\mathrm{F}_{1}$ to the juvenile albino parent produced $\mathrm{BC}_{1}$ progeny that segregated 1 normal : 1 juvenile albino. The $\mathrm{F}_{2}$ progeny segregated 3 normal : 1 juvenile albino. Three other populations, segregated in the expected ratio of 3 normal : 1 juvenile albino (Table 1). These results suggest that juvenile albino is controlled by a single recessive nuclear gene, designated ja. This confirms our previous suggestion based on preliminary data (Zhang and Rhodes, 1994).

Relationship between juvenile albino and delayed green. The previously described virescent mutant dg (Rhodes, 1986; Zhang et al., 


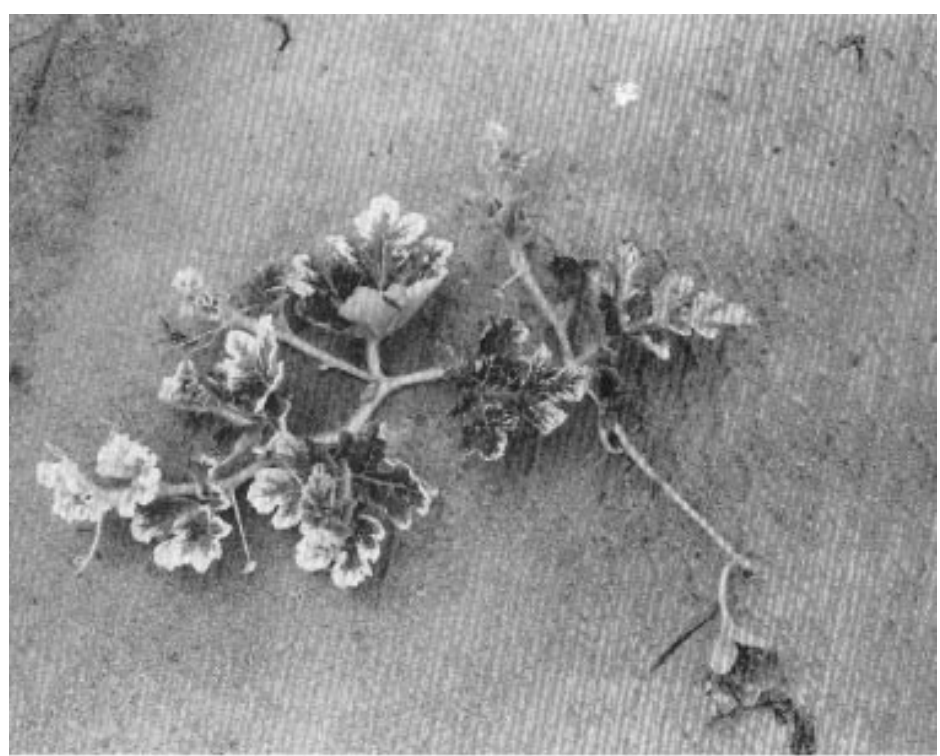

Fig. 2. A shoot of a juvenile albino watermelon plant grown in the field in early June. Note the color difference between primary and secondary shoot.

1996) is the only chlorophyll deficiency mutant in watermelon that is similar to the ja mutant. $\mathrm{F}_{1}$ progeny between homozygous $j a$ and $d g$ were normal green. Backcrossing $\mathrm{F}_{1}$ to the ja parent 'Dixielee' produced progeny that segregated 1 normal : 1 ja. The $\mathrm{F}_{2}$ progeny segregated in the ratio of 9 normal : 3 delayed-green : 4 ja (Table 2). Individuals with genotype jajadgdg were indistinguishable from individuals with genotype $j a j a D g_{-}$. These results are consistent with the hypothesis that the two watermelon virescent genes $j a$ and $d g$ are inherited independently.

Regulation of juvenile albino expression. Under conditions that activate the expression of the ja gene, the mutant grows very poorly or even senesces. However, under conditions that inhibit ja gene expression the mutant grows almost as normally as the wild-type. Understanding the regulation of $j a$ gene expression is important for maintaining and using this mutant in genetic studies and breeding.

Fig. 3. Flowers of the juvenile albino mutant (top) and the wild-type (bottom).

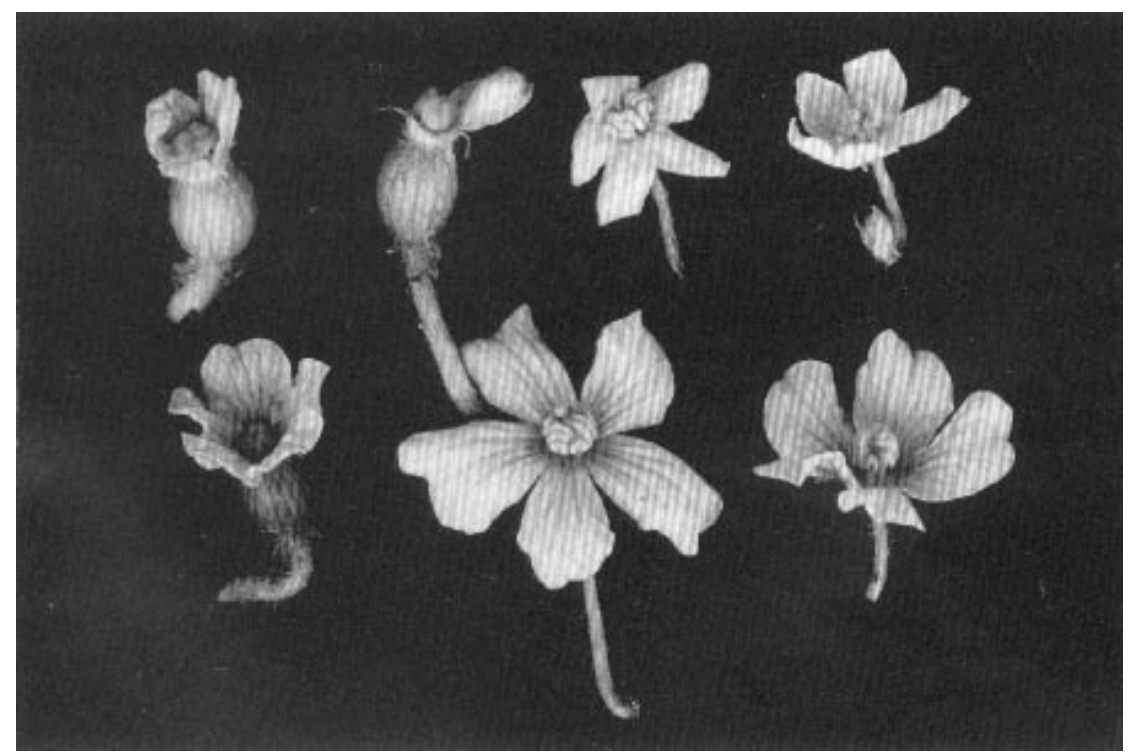

There are chlorophyll mutants that are light or temperature sensitive in maize (Hopkins et al., 1980; Hopkins and Elfman, 1984; Millerd and McWilliam, 1968), cotton (Benedict and Kohel, 1968), cucumber (Whelan, 1972) and watermelon (Provvidenti, 1994). We first speculated that the ja mutant was sensitive to low temperature because mutant seedlings were always severely albino in the early spring when it was cold, especially at night. When the mutant seedlings were provided a 15 -h photoperiod, neither low $\left(5 \pm 2^{\circ} \mathrm{C}\right)$ nor high $\left(23 \pm 2^{\circ} \mathrm{C}\right)$ night temperature resulted in ja phenotype in seedlings of the mutant (Table 3). The mutant was almost as green as the wildtype. Like the wild-type, the mutant plants exposed to low night temperature were slightly greener than those exposed to high night temperature. As shown in Table 3, temperature affected seedling growth of the mutant and the wild-type in the same manner. Low night temperature significantly reduced seedling fresh weight and height of both mutant and wildtype. The insignificant genotype and treatment interaction $(P$ $=0.6045$ for fresh weight and $P=0.1232$ for seedling height) confirms that temperature does not differentially affect the ja mutant and its wild-type. Temperature, therefore, is not likely the environment factor that regulates the expression of the $j a$ gene.

The ja mutant responded to daylength very differently than did the wild-type. Although leaf color of the wild-type appeared the same under short and long days, the typical ja phenotype occurred under short days and produced almost normal seedlings under long days. As shown in Table 4, the ja mutant produced only half the fresh weight of the wild-type under short days. However, the mutant produced as much tissue as the wild-type under long days. Chlorophyll a was not increased in the wild-type when a longer photoperiod was provided. However, chlorophyll a was almost doubled in the seedlings of the ja mutant under long days. A slight increase in chlorophyll b was also observed in the ja mutant when long days were provided, but no changes were observed in the wild-type. The seedlings of the ja mutant had a higher chlorophyll a:b ratio than the wild-type when expression of $j a$ was inhibited under long days. In contrast to our results, Hopkins et al. (1980) observed a significantly higher chlorophyll a : b ratio in the maize $O y-y g$ mutant than in the wild-type when expression of $O y-y g$ was enhanced under high light intensity conditions. Overall, daylength did not influence chlorophyll $\mathrm{a}: \mathrm{b}$ ratio of the ja mutant and the wild-type. As indicated by the significant genotype and treatment interaction $(P=0.0001,0.0004$, and 0.0474 for fresh weight, chlorophyll a, and chlorophyll b, respectively), the ja mutant responded to daylength very differently from the wild-type. Daylength, therefore, is one environmental factor regulating the expression of the $j a$ gene. Expression of the $j a$ gene is activated in the mutant by a short photoperiod. The current study did not determine the minimum daylength that significantly inhibits the expression of $j a$ gene and allows normal development of the mutant. Based on field observations made over the last 3 years, the minimum daylength required for normal growth of the ja mutant is about $14 \mathrm{~h}$. Controlled experiments are needed to define more precisely the minimum photoperiod and determine if there is quantitative expression of the $j a$ gene and/or the ja phenotype.

There are chlorophyll mutants whose expres- 


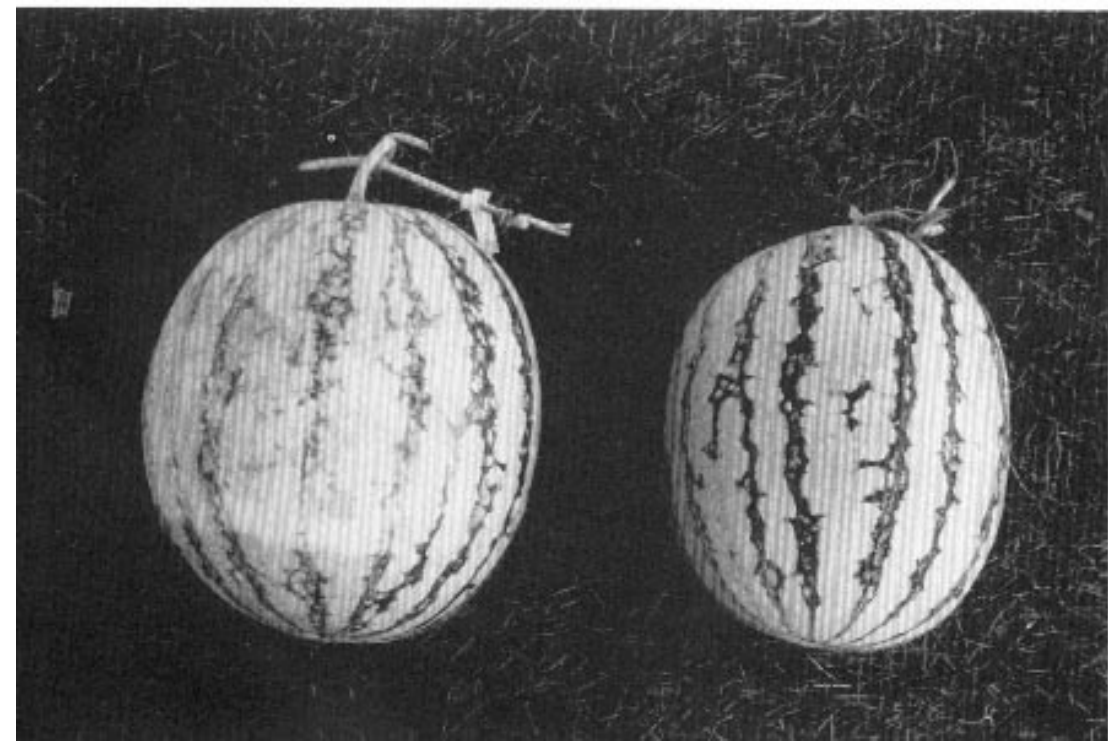

Fig. 4. Fruit of the juvenile albino mutant (left) and the wild-type (right).

sion is regulated by light intensity in maize (Hopkins et al., 1980), cotton (Benedict and Kohel, 1968) and cucumber (Whelan, 1972). The expression of $j a$ is not likely regulated by light intensity because the mutant produced the typical albino phenotype in the greenhouse and field in the early spring, where the light intensity varied several fold. The typical albino phenotype was also observed in the mutant plants grown in the greenhouse in the winter, where the light intensity was often very low because of the cloudy weather. No other chlorophyll-deficiency mutations whose expression is regulated by daylength have been reported for cucurbit crops or other plant species. Therefore, the ja watermelon mutant described here is a very rare, if not unique, virescent mutant where gene expression is regulated by daylength.

The possibility of phytochrome involvement in the regulation of $j a$ expression was investigated after the role of daylength in $j a$ expression was documented. In this experiment, no evidence of the involvement of phytochrome in the regulation of the ja expression was found. Brief exposures (15 min) of seedlings of the ja mutant and wild-type to irradiances of monochromatic $\mathrm{R}$ (the treatments $\mathrm{R}$ and FR + R) or FR (the treatments FR and R + FR) light at the end of the 8-h photoperiod did not alter the albino phenotype of the ja mutant. Phytochrome-regulated seedling growth in both geno- types was similar to that described by Decoteau and Friend (1991) in 'Sugar Baby' watermelon seedlings. As shown in Table 5, the seedlings receiving $R+F R$ light treatment had greater fresh weight. Both the ja mutant and wild-type had similar response to the treatments where fresh weight was measured, as indicated by insignificant interaction between genotype and treatment $(P=0.6130)$. Also, the hypocotyl and petiole of the first and second true leaf were longer in seedlings receiving FR and $\mathrm{R}+$ FR light treatments regardless of the genotype. However, more elongation of hypocotyl and leaf petiole was stimulated by FR and R + FR treatments in wildtype than in mutant seedlings as indicated by significant interaction between genotype and treatment. This was probably due to an insufficient supply of carbohydrates to support FR stimulated elongation growth in the ja mutant. In fact, 3 out of 16 ja seedlings receiving FR treatment were dead or close to death by the end of the experiment.

The ja mutant is useful for genetic studies and watermelon breeding. The ja mutant is an ideal seedling marker in genetic studies because it is unambiguously differentiated from the wild-type with green cotyledons and greenish hypocotyl, as soon as the seedling emerges from soil. When this mutant is used to study gene flow in watermelon populations, large progeny tests can be accomplished in a short time in limited space. If the $j a$ gene is introduced into the seed parent of a hybrid variety, genetic purity of the hybrid seed can be tested in the greenhouse or laboratory in about 10 days instead of in the field, which requires two months or longer. This gene will also be helpful for detecting and eliminating off-types existing in an inbred line before the off-type produces pollen, resulting in further genetic contamination. Combining $j a$ and $m s$ (Zhang and Wang, 1990; Zhang et al., 1994) should permit commercial hybrid seed production without hand-pollination. We have been working on the development of a male-sterile line with the ja seedling marker since the discovery of $j a$ in one of the populations related to male-sterility breeding in 1992 (Zhang and Rhodes, 1994). Unpublished data indicate that this male-sterile line with the ja seedling marker produced a higher frequency of true hybrids than the male-sterile line with the dg seedling marker under open-pollination conditions (Zhang et al., 1996).

In summary, juvenile albino is a new virescent mutant in

Table 3. Effects of night temperature, low $\left(5 \pm 2{ }^{\circ} \mathrm{C}\right)$ vs. high $\left(23 \pm 2{ }^{\circ} \mathrm{C}\right)$, on seedling growth of ja 'Dixielee' and its wild-type watermelon. ${ }^{\mathrm{Z}}$

\begin{tabular}{|c|c|c|c|c|}
\hline Treatment & Genotype & & Fresh wt (g)y & Seedling ht $(\mathrm{cm})^{\mathrm{y}}$ \\
\hline \multirow[t]{3}{*}{ Low temperature } & ja ja & & $4.4 \pm 1.5$ & $7.8 \pm 2.4$ \\
\hline & $J a J a$ & & $8.0 \pm 1.2$ & $14.5 \pm 2.2$ \\
\hline & & Mean & $6.2 \pm 2.3$ & $11.2 \pm 4.1$ \\
\hline \multirow[t]{3}{*}{ High temperature } & $\mathrm{j} a \mathrm{ja}$ & & $6.4 \pm 1.1$ & $14.5 \pm 3.4$ \\
\hline & Ja Ja & & $10.3 \pm 1.1$ & $23.7 \pm 4.0$ \\
\hline & & Mean & $8.3 \pm 2.3$ & $19.2 \pm 5.9$ \\
\hline Factor & & & & \\
\hline Genotype & & & 0.0001 & 0.0001 \\
\hline Treatment & & & 0.0001 & 0.0001 \\
\hline Genotype $\times$ treatment & & & 0.6043 & 0.1232 \\
\hline
\end{tabular}

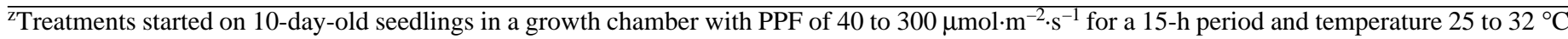
during day in the experiment period.

${ }^{\mathrm{y}}$ Mean \pm SD. 
Table 4. Effects of day length, short day $(8 \mathrm{~h}) \mathrm{vs}$. long day $(15 \mathrm{~h})^{\mathrm{z}}$, on shoot fresh weight $(\mathrm{FW})$, chlorophyll a $\left(\mathrm{a}, \mathrm{mg}^{-\mathrm{g}^{-1}}\right.$ leaf $)$, chlorophyll b (b, mg. $\mathrm{g}^{-1}$ leaf), and chlorophyll $\mathrm{a}: \mathrm{b}$ ratio $(\mathrm{a}: \mathrm{b})$ of seedlings of juvenile albino 'Dixielee' and its wild-type watermelon. ${ }^{\mathrm{y}}$

\begin{tabular}{|c|c|c|c|c|c|}
\hline Treatment & Genotype & $\mathrm{FW}(\mathrm{g})^{\mathrm{w}}$ & $a^{w}$ & $b^{w}$ & $a: b^{w}$ \\
\hline \multirow[t]{2}{*}{ Short day } & ja ja & $4.9 \pm 1.6$ & $0.7 \pm 0.1$ & $0.3 \pm 0.05$ & $2.7 \pm 0.3$ \\
\hline & $J a J a$ & $9.4 \pm 1.8$ & $1.7 \pm 0.1$ & $0.7 \pm 0.06$ & $2.6 \pm 0.1$ \\
\hline \multirow[t]{2}{*}{ Long day } & ja ja & $11.2 \pm 1.9$ & $1.3 \pm 0.2$ & $0.4 \pm 0.07$ & $2.9 \pm 0.1$ \\
\hline & $J a J a$ & $12.5 \pm 0.9$ & $1.8 \pm 0.1$ & $0.7 \pm 0.07$ & $2.5 \pm 0.1$ \\
\hline Factor & & & & & \\
\hline Genotype & & 0.0001 & 0.0001 & 0.0001 & 0.0008 \\
\hline Treatment & & 0.0001 & 0.0001 & 0.0001 & 0.8443 \\
\hline Genotype $\times$ treatment & & 0.0001 & 0.0004 & 0.0474 & 0.1251 \\
\hline
\end{tabular}

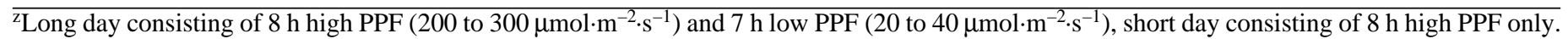

yTwo-week-old seedlings grown in the growth chamber were used for this experiment.

${ }^{\mathrm{w}}$ Mean \pm SD.

Table 5. Effects of end-of-day light, red (R), far-red (FR), R + FR, FR + R and dark (control), on seedling growth (shoot fresh weight = FW, hypocotyl length $=\mathrm{HL}$, first leaf petiole length $=1$ st PL, and second leaf petiole length $=2$ nd PL) of $j a$ 'Dixielee' and wild-type watermelon. ${ }^{\mathrm{Z}}$

\begin{tabular}{|c|c|c|c|c|c|}
\hline Treatment & Genotype & $\mathrm{FW}(\mathrm{g})^{\mathrm{y}}$ & $\mathrm{HL}(\mathrm{cm})^{\mathrm{y}}$ & 1st PL $(\mathrm{cm})^{\mathrm{y}}$ & 2nd PL $(\mathrm{cm})^{\mathrm{y}}$ \\
\hline \multirow[t]{2}{*}{ Control } & ja ja & $0.7 \pm 0.1$ & $6.2 \pm 0.7$ & $0.7 \pm 0.3$ & $0.4 \pm 0.2$ \\
\hline & $J a J a$ & $2.2 \pm 0.7$ & $7.6 \pm 0.7$ & $2.9 \pm 0.4$ & $2.4 \pm 0.4$ \\
\hline \multirow[t]{2}{*}{$\mathrm{R}$} & ja ja & $0.9 \pm 0.3$ & $5.2 \pm 1.1$ & $0.9 \pm 0.4$ & $0.5 \pm 0.3$ \\
\hline & $J a J a$ & $2.5 \pm 0.6$ & $6.7 \pm 1.0$ & $3.2 \pm 0.4$ & $2.5 \pm 0.7$ \\
\hline \multirow[t]{2}{*}{$\mathrm{FR}+\mathrm{R}$} & ja ja & $0.7 \pm 0.3$ & $5.7 \pm 0.8$ & $0.7 \pm 0.3$ & $0.4 \pm 0.2$ \\
\hline & $J a J a$ & $2.4 \pm 0.3$ & $7.8 \pm 0.8$ & $3.0 \pm 0.3$ & $2.5 \pm 0.4$ \\
\hline \multirow[t]{2}{*}{ FR } & ja ja & $0.6 \pm 0.4$ & $7.6 \pm 1.1$ & $0.5 \pm 0.2$ & $0.2 \pm 0.1$ \\
\hline & $J a J a$ & $2.6 \pm 0.6$ & $12.4 \pm 1.3$ & $5.4 \pm 0.9$ & $3.6 \pm 1.1$ \\
\hline \multirow[t]{2}{*}{$\mathrm{R}+\mathrm{FR}$} & ja ja & $1.2 \pm 0.4$ & $10.1 \pm 3.2$ & $1.6 \pm 0.9$ & $0.9 \pm 0.9$ \\
\hline & $J a J a$ & $3.0 \pm 0.8$ & $13.4 \pm 1.4$ & $5.6 \pm 1.2$ & $4.1 \pm 1.6$ \\
\hline Factors & & \multicolumn{4}{|c|}{$P$ value } \\
\hline Genotype & & 0.0001 & 0.0001 & 0.0001 & 0.0001 \\
\hline Treatment & & 0.0121 & 0.0001 & 0.0001 & 0.0003 \\
\hline Genotype $\times$ treatment & & 0.6130 & 0.0129 & 0.0001 & 0.0227 \\
\hline
\end{tabular}

${ }^{\mathrm{z}}$ Seven-day-old seedlings grown in the growth chamber were used in this experiment. Plants were provided PPF of $300 \mu \mathrm{mol} \cdot \mathrm{m}^{-2} \cdot \mathrm{s}^{-1} \mathrm{during}$ a 8 -h period of day. The day/night temperature cycle averaged $27 / 21^{\circ} \mathrm{C}$.

yMean \pm sD.

watermelon that is controlled by a single, recessive, nuclear gene. A gene symbol ja is proposed for this mutation. The mutants ja and $d g$, the previously reported virescent mutant, are located at independent loci. Expression of the ja gene is regulated by daylength. Long days inhibit the expression of $j a$, and therefore, the mutant grows almost normally when long days are provided. Under short days, chlorophyll synthesis and/or accumulation in the ja mutant is severely impaired, and the mutant grows very poorly or even senesces. Knowledge of involvement of daylength in the regulation of $j a$ expression is useful for properly maintaining and propagating the mutant. This mutant can be maintained and propagated in areas where long days (longer than $14 \mathrm{~h}$ ) are available. The ja mutant provides a useful seedling marker for watermelon genetic study and breeding, as well as unique material for studying photosynthesis in plants.

\section{Literature Cited}

Benedict, C.R. and R.J. Kohel. 1968. Characteristics of a virescent cotton mutant. Plant Physiol. 43:1611-1616.

Decoteau, D.R. and H.H. Friend. 1991. Phytochrome-regulated growth of young watermelon plants. J. Amer. Soc. Hort. Sci. 116:512-515.

Handel, S.N. 1982. Dynamics of gene flow in an experimental population of Cucumis melo (Cucurbitaceae). Amer. J. Bot. 69:1583-1546.
Hoffman, J.C. and P.E. Nugent. 1973. Inheritance of a virescent mutant in muskmelon. J. Hered. 64:311-312.

Hopkins, W.G., D.B. Hayden, and M.G. Neuffer. 1980. A light-sensitive mutant in maize (Zea mays L.) I. Chlorophyll, chlorophyll-protein and ultrastructural studies. Z. Pflanzenphysiol. Bd. 99: 417-426.

Hopkins, W.G. and B. Elfman. 1984. Temperature-induced chloroplast ribosome deficiency in virescent maize. J. Hered. 75:207-211.

McCreight, J.D. and G.W. Bohn. 1979. Descriptions, genetics, and independent assortment of red stem and pale in muskmelon (Cucumis melo L.). J. Amer. Soc. Hort. Sci. 104:721-723.

Millerd, A. and J.R. McWilliam. 1968. Studies on a maize mutant sensitive to low temperature I. influence of temperature and light on the production of chloroplast pigments. Plant Physiol. 43:1967-1972.

Nugent, P.E. and J.C. Hoffman. 1981. Natural cross pollination in four andromonoecious seedling marker lines of muskmelon. HortScience 16:73-74.

Nugent, P.E. 1994. Homozygous, monoecious, virescent melon C879-J3. HortScience 29:46.

Provvidenti, R. 1994. Inheritance of a partial chlorophyll deficiency in watermelon activated by low temperature at the seedling stage. HortScience 29:1062-1063.

Rhodes, B.B. 1986. Genes affecting foliage color in watermelon. J. Hered. 77:134-135.

Rhodes, B.B., J.N. Zhang, X.P.Zhang, and W.C. Bridges. 1992. Improved germination rate after 8 years in certain watermelon families. Cucurbit Genet. Coop. Rpt. 15:82-83. 
Rhodes, B.B. and X.P. Zhang. 1995. Gene list for watermelon. Cucurbit Genet. Coop. Rpt. 18:69-84.

Robinson, R.W., H.M. Munger, T.W. Whitaker, and G.W. Bohn. 1976. Genes of the Cucurbitaceae. HortScience 11:554-568.

SAS Institute. 1988. SAS/STAT user's guide. SAS Institute, Cary, N.C. Somerville, C.R. 1986. Analysis of photosynthesis with mutants of higher plants and algae. Annu. Rev. Plant Physiol. 37:467-507.

Taylor, W.C. 1989. Regulatory interactions between nuclear and plastid genomes. Annu. Rev. Plant Physiol. Plant Mol. Biol. 40:211-233.

Warid, A. and A.A. Abd-El-Hafez. 1976. Inheritance of marker genes of leaf color and ovary shape in watermelon, Citrullus vulgaris Schrad. The Libyan J. Sci. 6A:1-8.

Wetzel, C.M., C.-Z. Jiang, L.J. Meehan, D.F. Voytas, and S.R. Rodermel. 1994. Nuclear-organelle interaction mutant of Arabidopsis is plastid autonomous and impaired in carotenoid biosynthesis. Plant J. 6:161175 .

Whelan, E.D.P. 1972. Inheritance of a radiation-induced light sensitive mutant of cucumber. J. Amer. Soc. Hort. Sci. 97:765-767.

Whelan, E.D.P., P.H. Williams, and Z. Abul-Hayja. 1975. The inheritance of two induced cotyledon mutants of cucumber. HortScience 10:267269.

Witham, F.H., D.F. Blaydes, and R.M. Devlin. 1971. Experiments in plant physiology. Van Nostrand Reinhold Co., New York. p. 55-58.

Zhang, X.P. and M. Wang. 1990. A genetic male-sterile $(m s)$ watermelon from China. Cucurbit Genet. Coop. Rpt. 13:45.

Zhang, X.P. and B.B. Rhodes. 1994. A new morphological marker in watermelon, juvenile albino (ja). Cucurbit Genet. Coop. Rpt. 17:101.

Zhang, X.P., H.T. Skorupska, and B.B. Rhodes. 1994. Cytological expression of the male-sterile $m s$ mutant in watermelon. J. Hered. 85:279-285.

Zhang, X.P., B.B. Rhodes, W.V. Baird, H.T. Skorupska, and W.C. Bridges. 1996. Development of genic male-sterile watermelon lines with delayed-green seeding marker. HortScience (In press.)

Zink, F.W. 1977. Linkage of virescent foliage and plant growth habit in muskmelon. J. Amer. Soc. Hort. Sci. 102:613-615. 